\title{
Fulminant liver failure in a street runner: Effects of heat stroke
}

\author{
Renata Rodrigues Teixeira de Castro ${ }^{1-5 *}$ ๑ , Rubens Costa Filho ${ }^{3}$, Antonio Claudio lucas da Nóbrega 2,4 \\ ${ }^{1}$ Faculdade de Medicina, Universidade Iguaçu, Nova Iguaçu, RJ, Brazil \\ ${ }^{2}$ Autonomic and Cardiovascular Reactivity Laboratory, Hospital Pró-Cardíaco, Rio de Janeiro, RJ, Brazil \\ ${ }^{3}$ Intensive Care Unit, Hospital Pró-Cardíaco, Rio de Janeiro, RJ, Brazi \\ ${ }^{4}$ Cardiovascular Science Graduate Program, Universidade Federal Fluminense, Niterói, RJ, Brazi \\ ${ }^{5}$ Cardiology Service, Hospital Naval Marcíio Dias, Marinha do Brasil, Rio de Janeiro, RJ, Brazil
}

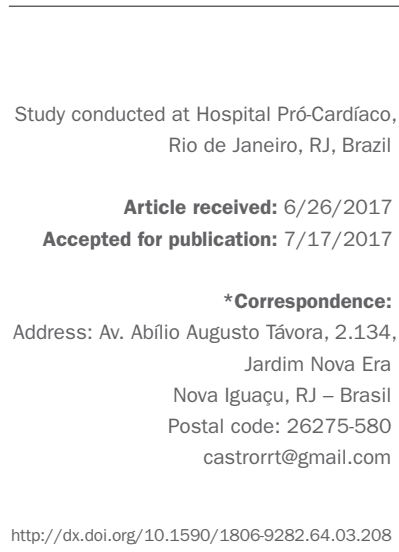

\section{INTRODUCTION}

Running is one of the most democratic sports, requiring few resources for its practice. In recent years, the number of participants in street races has been growing exponentially. A survey by the São Paulo State Athletics Federation (FPA, in the Portuguese acronym) shows an increase of about $10 \%$ per year compared to the number of participants between the years 2010 and 2014 (http://www.atletismofpa. org.br/Corrida-de-Rua/Estat\%C3\%ADstica-2014). The growth of street races positively influences the regular practice of physical exercise by its competitors, but it is important to recognize that the risks also tend to grow. Therefore, it is critical that such events be practiced safely and with adequate contingency plans, especially with regard to responding to medical emergencies by trained professionals.

The objective of this article was to report a case of fulminant liver failure in a street runner who developed heat stroke.

\section{Case report}

Our patient is a 35 year-old male from London, England. He was married, worked in the marketing department of a tobacco company, and had been living in Rio de Janeiro for six months. He was participating in a relay marathon $(10 \mathrm{~km}$ race for each participant) at Aterro do Flamengo, Rio de Janeiro, on a summer morning (local temperature of $35^{\circ} \mathrm{C} / 95^{\circ} \mathrm{F}$ ), when he lost consciousness and was taken by ambulance to a public municipal hospital. According to reports, the patient was hyperthermic (axillary temperature $[\mathrm{TAx}]=40.2^{\circ} \mathrm{C} / 104.3^{\circ} \mathrm{F}$ ) and had tachycardia (regular rhythm, heart rate $[\mathrm{HR}]=140 \mathrm{bpm}$ ), psychomotor agitation and disorientation. Other than that, the physical examination was normal. He was given venous esmolol hydrochloride $(150 \mathrm{mg} / 5$ minutes $)$ and hydration with saline solution $(1,000 \mathrm{~mL})$. Five hours later, he was transferred to a private hospital. He was still disoriented and agitated, with $\mathrm{TAx}=$ $39^{\circ} \mathrm{C} / 102.2^{\circ} \mathrm{F}, \mathrm{HR}=132 \mathrm{bpm}$, blood pressure $(\mathrm{BP})=160$ x $80 \mathrm{mmHg}$; respiratory rate $(\mathrm{RR})=22$ breaths per minute, peripheral $\mathrm{O}_{2}$ saturation $=97 \%$, capillary blood glucose $=$ $104 \mathrm{mg} / \mathrm{dL}$. Other than that, the physical examination was also normal. Thorough venous hydration was performed, yielding relative improvement of the patient's state of consciousness. We requested more clinical tests (D1) (Table 1). An electrocardiogram revealed sinus tachycardia, without other abnormalities, while an echocardiogram showed only hyperkinesia. Arterial blood gas (ABG): $\mathrm{pH}=7.45$; $\mathrm{pO} 2=$ $94.7 \mathrm{mmHg}$; $\mathrm{pCO} 2=29.3 \mathrm{mmHg}$; base excess $(\mathrm{BE})=-8.5$; $\mathrm{HCO} 3=15 \mathrm{mmol} ; \mathrm{O}_{2}$ saturation $=98 \%$. Urine sediment examination revealed hemoglobinuria. Head computed tomography (no alterations) and face sinuses were performed, the latter revealing maxillary sinusitis. IV hydration was maintained and antibiotic therapy with amoxicillin/ clavulanate was started for sinusitis treatment.

The following day, the opinion of a specialist in sports medicine was requested. The patient remained very sleepy 
and so the story was taken from a coworker who had accompanied him in the race. The coworker informed that beginning in the fifth kilometer of the race, the patient started to breathe "in a strange way" and that in the ninth kilometer he did not respond to any request and used disconnected words, to the point where, in the tenth kilometer, the patient lost consciousness and fell to the ground. It was not possible to obtain details on the hydration measures adopted during the race. Despite having participated in races in England, this was his first race in Rio de Janeiro. He had not been training over the past few months. He made regular use of alcohol (not quantified) and had attended a company party the day before the race. In addition, there was a history of influenza-like illness in the previous week, treated with non-steroidal anti-inflammatory drugs. There were no other relevant data in the history and it was not possible to gather information about the patient's previous family or disease history.

Considering the diagnosis of heat stroke and the possibility of rhabdomyolysis, we implemented vigorous hydration ( $6 \mathrm{~L} /$ day of saline solution), maintenance of the patient in a refrigerated environment and alkalinization of urine with bicarbonate, leading to improvement of his general condition. In the following hours, the patient regained consciousness, with proper orientation and without psychomotor agitation. He was tachypneic $(\mathrm{RR}=24$ breaths per minute), with $\mathrm{BP}=120 \times 80$ $\mathrm{mmHg}, \mathrm{Tax}=37^{\circ} \mathrm{C} / 98.6^{\circ} \mathrm{F}$. Serum lactate $=1.9 \mathrm{mmol} / \mathrm{L}$. However, the next day, there was clinical worsening again, progressing to coma (Glasgow Coma Scale $=4$ ). Orotracheal intubation was performed and the patient was transferred to the ICU (test results shown in Table 2, D2). Scores usually adopted in intensive care yielded SOFA $=8$ and APACHE II $=10$. As shown in Table 1 , the patient progressed with rhabdomyolysis, thrombocytopenia, coagulopathy and hepatic failure. Thorough hydration and alkalinization of urine were maintained. Serologies and antibody testing were negative for HIV, and hepatitis B and C. Toxicological tests were also negative. In order to avoid potential bleeding, aprotinin and vitamin $\mathrm{K}$ were administered.

This was therefore a case of severe fulminant liver failure (Child-Turcotte-Pugh score: 12 points), resulting from heat stroke, an event with mortality estimated to be $65-90 \%$ at one year. The possibility of liver transplantation was considered. However, as shown in Table 1, after nine days, the patient progressed with important laboratory and clinical improvement (D9), being discharged in good general condition the following week.
TABLE 1 Blood test results, patient's evolution.

\begin{tabular}{|c|c|c|c|c|}
\hline Test & D1 & D2 & D3 & D9 \\
\hline Hemoglobin $(\mathrm{g} / \mathrm{dL})$ & 11.9 & 13.2 & 12.8 & 11.8 \\
\hline WBC count $\left(\mathrm{n} / \mathrm{mm}^{3}\right)$ & 11,000 & 9,600 & 7,800 & 8.9 \\
\hline Platelet count $\left(\mathrm{n} / \mathrm{mm}^{3}\right)$ & 138,000 & 42,000 & 50,000 & 203,000 \\
\hline Potassium (mEq/L) & 3.6 & 3.4 & 3.4 & 4.3 \\
\hline Sodium (mEq/L) & 146 & 144 & 142 & 138 \\
\hline Calcium (g/dL) & 9.0 & & 8.5 & 8.7 \\
\hline Phosphorus (g/dL) & & & 2.2 & 4.3 \\
\hline Urea (mg/dL) & 39 & 42 & 21 & 26 \\
\hline Creatinine (mg/dL) & 1.7 & 1.6 & 1.3 & 1.1 \\
\hline CPK $(U / L)$ & 278 & 6,496 & 10,220 & 350 \\
\hline Lactate (mmol/L) & 5.9 & 1.9 & 2.4 & 1.0 \\
\hline Total bilirubin (mg/dL) & & 2.5 & 1.9 & 1.0 \\
\hline $\begin{array}{l}\text { Gamma-glutamyl } \\
\text { transferase }(\mathrm{U} / \mathrm{L})\end{array}$ & & 139 & 135 & 113 \\
\hline $\begin{array}{l}\text { Glutamic pyruvic } \\
\text { transaminase }(U / L)\end{array}$ & 35 & 2,329 & 4,985 & 100 \\
\hline $\begin{array}{l}\text { Glutamic oxaloacetic } \\
\text { transaminase }(\mathrm{U} / \mathrm{L})\end{array}$ & 51 & 1,596 & 3,836 & 120 \\
\hline Alkaline phosphatase (U/L) & & 82 & & 60 \\
\hline Fibrinogen $(\mathrm{U} / \mathrm{L})$ & 212 & & & 1 \\
\hline $\begin{array}{l}\text { Activated partial } \\
\text { thromboplastin time (\%) }\end{array}$ & 59 & 18 & 11 & 89 \\
\hline INR & 1.39 & 3.67 & 5.69 & 1.5 \\
\hline D-dimer (ng/mL) & & 7,972 & 8,801 & \\
\hline $\mathrm{pH}$ urine & 5.0 & 5.0 & & \\
\hline
\end{tabular}

WBC: white blood cells; CPK: creatine phosphokinase; INR: International Normalized Ratio; $\mathrm{D}$ : day of hospitalization.

\section{TABLE 2 Stages of heat stroke.}

\begin{tabular}{ll} 
Stage & Characteristics \\
\hline Hyperthermic & Neurologic deficit and hyperthermia \\
\hline Hematologic and enzymatic & Leukocytosis, coagulopathy, increased \\
& cellular enzymes \\
\hline Renal and hepatic impairment & Acute kidney and liver failure \\
\hline
\end{tabular}

\section{Discussion}

Heat stroke is a potentially fatal condition characterized by central body temperature above $40^{\circ} \mathrm{C} / 104^{\circ} \mathrm{F}$ and central nervous system disorders including delirium, seizures, and coma. ${ }^{1}$ US data show that there were 7,000 heat deaths in that country between 1979 and $1997 .{ }^{2}$ According to Casa et al., 3,4 these deaths continue to occur due to lack of information regarding diagnosis and treatment of heat stroke. Although there is no Brazilian statistic, considering the weather, we can infer that heat stroke also causes victims in the country. 
Heat stroke can be induced by exposure to high temperatures (unrelated to physical exercise) or secondary to strenuous physical exercise. Bouchama \& Knochel $^{1}$ proposed a pathophysiological definition for heat stroke that applies perfectly to the case reported here: "A form of hyperthermia associated with a systemic inflammatory response leading to a syndrome of multiorgan dysfunction in which encephalopathy predominates." The main complications of heat stroke are related to multiorgan dysfunction. Three phases are proposed for heat stroke, as shown in Table 2.

Exposure to heat or strenuous exercise at high temperatures does not always progress to heat stroke. Genetic factors may determine the susceptibility of certain individuals to the development of heat stroke, such as changes in the production of cytokines, coagulation proteins and heat shock proteins involved in thermal adaptation. ${ }^{5}$

In the case reported here, it is possible to identify some factors that probably contributed to the development of heat-induced multiorgan organic failure. The patient had not become properly acclimatized. Although he had been in Rio de Janeiro for about six months, he had not been training since he moved from England. Armstrong et al. ${ }^{6}$ demonstrated the importance of acclimatization, not only regarding environmental temperature, but also in relation to the performance of training in the competition clothing in order to avoid the occurrence of heat stroke.

The initial care provided to the patient should also be carefully evaluated. The low rate of suspicion of heat stroke by first responders clearly contributed to the catastrophic progression of the patient's condition. Early recognition of heat stroke and proper treatment at the competition site could have prevented multiorgan dysfunction. Measures to facilitate heat loss should have been promptly initiated. ${ }^{4}$ It is known that rapid cooling and adequate management of circulatory shock can prevent tissue damage and death. ${ }^{7}$ Although there is no preferred method for cooling, immersion in ice water proved to be effective in cases of exercise-induced heat stroke. Although no controlled studies comparing the effectiveness of immersion and evaporative cooling were conducted, a meta-analysis published in 2007 suggests that immersion in ice water is the most effective method. ${ }^{7}$ However, this method is less practical, making it difficult to access submerged body parts and requiring continuous monitoring of patients due to the risk of drowning.

Some medications can facilitate the occurrence of heat stroke, namely alcohol, alpha-adrenergics, amphetamines, anticholinergics, antihistamines, benzodiazepines, beta-blockers, calcium channel blockers, diuretics, laxatives, neuroleptics and tricyclic antidepressants. ${ }^{8,9}$ Alcohol use on the eve of competition and beta-blocker administration at first care may have contributed to the unfavorable outcome in this case.

Finally, we must comment on the occurrence of liver failure. Weigand et al. ${ }^{10}$ reported two cases of liver failure associated with exertion-induced heat stroke, suggesting that heat stroke and exhaustion were underestimated causes of liver failure. Later, Garcin et al. ${ }^{11}$ followed a cohort of 110 patients with heat stroke and concluded that $22.7 \%$ (25 subjects) of them progressed with liver failure.

Recently, the Acute Liver Failure Study Group ${ }^{12}$ identified eight patients with heat stroke in a prospective American cohort of 2,675 patients with acute liver injury. One of these patients underwent liver transplantation. In fact, cases in which hepatic transplants were performed under these conditions are rare. ${ }^{13}$

Hepatocellular necrosis is consequent to thermal and circulatory shock, endotoxemia and high concentration of cytokines and acute-phase proteins. ${ }^{11}$ However, the only predictor for the occurrence of liver failure was hypophosphatemia, also seen in our patient. ${ }^{11,14}$ It is noteworthy that there is no evidence that hypophosphatemia is the cause of liver dysfunction.

A report from the Acute Liver Failure Study Group found $25 \%$ of deaths in patients with liver failure secondary to heat stroke diagnosed between January 1988 and April 2015 in the United States. ${ }^{12}$ Varghese et al. ${ }^{15}$ followed 28 victims of heat stroke and concluded that the high mortality of these cases is due to multiple organic dysfunction.

Predictive factors for the development of multiple organ dysfunction in these patients include: increased creatine phosphokinase (> 1,000 U/L), metabolic acidosis and increased liver enzymes.

\section{Conclusion}

Heat stroke is a potentially fatal entity whose complications can be avoided if simple therapeutic measures are promptly initiated. Awareness of health professionals working in sports and emergency settings is crucial to achieving the best prognosis for these patients.

\section{Resumo}

Insuficiência hepática fulminante em corredor de rua: efeitos do colapso por calor

Apresentamos um caso de insuficiência hepática decorrente de colapso por calor. Trata-se de entidade pouco conhecida e, provavelmente, subdiagnosticada em nosso país. 
Palavras-chave: Insuficiência Hepática. Golpe de Calor. Febre.

\section{References}

1. Bouchama A, Knochel JP. Heat stroke. N Engl J Med. 2002;346(25):1978-88.

2. Centers for Disease Control and Prevention (CDC). Heat-related illnesses, deaths, and risk factors: Cincinnati and Dayton, Ohio, 1999, and United States, 1979-1997. MMWR Morb Mortal Wkly Rep. 2000;49(21):470-3.

3. Casa DJ, Armstrong LE, Ganio MS, Yeargin SW. Exertional heat stroke in competitive athletes. Curr Sports Med Rep. 2005;4(6):309-17.

4. Casa DJ, Armstrong LE, Kenny GP, O’Connor FG, Huggins RA. Exertional heat stroke: new concepts regarding cause and care. Curr Sports Med Rep. 2012;11(3):115-23.

5. Brueckmann M, Hoffmann U, Borggrefe M. Beyond sepsis: activated protein C and heat stroke. Crit Care Med. 2006;34(7):2020-1.

6. Armstrong LE. Fatal heat stroke in football players. J Athl Train. 2010; 45(4):325-6

7. Bouchama A, Dehbi M, Chaves-Carballo E. Cooling and hemodynamic management in heatstroke: practical recommendations. Critical Care. 2007;11(3):R54
8. Glazer JL. Management of heatstroke and heat exhaustion. Am Fam Physician. 2005;71(11):2133-40

9. Carvalho AS, Rodeia SC, Silvestre J, Póvoa P. Exertional heat stroke and acute liver failure: a late dysfunction. BMJ Case Rep. 2016. doi: 10.1136/bcr2016-214434.

10. Weigand K, Riediger C, Stremmel W, Flechtenmacher C, Encke J. Are heat stroke and physical exhaustion underestimated causes of acute hepatic failure? World J Gastroenterol. 2007;13(2):306-9.

11. Garcin JM, Bronstein JA, Cremades S, Courbin P, Cointet F. Acute liver failure is frequent during heat stroke. World J Gastroenterol. 2008; 14(1):158-9.

12. Davis BC, Tillman H, Chung RT, Stravitz RT, Reddy R, Fontana RJ, et al. Heat stroke leading to acute liver injury \& failure: a case series from the Acute Liver Failure Study Group. Liver Int. 2017;37(4):509-13.

13. Takahashi K, Chin K, Ogawa K, Kasahara M, Sakaguchi T, Hasegawa S, et al. Living donor liver transplantation with noninvasive ventilation for exertional heat stroke and severe rhabdomyolysis. Liver Transpl. 2005;11(5):570-2

14. Salathé C, Pellaton C, Carron PN, Coronado M, Liaudet L. Acute liver failure complicating exertional heat stroke: possible role of hypophosphatemia. Curr Sports Med Rep. 2015;14(1):49-50

15. Varghese GM, John G, Thomas K, Abraham OC, Mathai D. Predictors of multi-organ dysfunction in heatstroke. Emerg Med J. 2005;22(3):185-7. 